\title{
Self vs. Organizational Employment: The Neglected Case of Positive Spillover
}

\begin{abstract}
Celf-employment is presented as enabling people to better balance their work and family roles but $\bigcup$ research on its effectiveness is equivocal. We collected survey data from 280 self- and organizationally-employed certified public accountants and conducted a multivariate analysis comparing positive spillover and conflict between the two groups. The self-employed reported less work-to-family conflict with no differences with respect to family-towork conflict or positive spillovers. However, there were different patterns between male and female subsamples: selfemployed males experienced less conflict and more positive spillover than male employees, whereas self-employed females had less of one form of conflict but more of the otber.
\end{abstract}

Keywords: positive spillover; work-family conflict; selfemployment; gender; accountants

Self-employment embodies the American dream for many, and the growth in self-employment over the last three decades suggests that more and more Americans are making that dream come true. Although estimates vary, approximately $19 \%$ of workers in the United States were self-employed in 2002, compared to $11.5 \%$ in 1973 (Bond, Thompson, Galinsky, \& Prottas, 2003; Quinn \& Staines, 1979). More men than women are self-employed, but self-employment is increasing more rapidly for women than men (DeMartino \& Barbato, 2003; Hughes, 2003).

Self-employment has long been considered a strategy for gaining control over inter-role conflict as individuals seek to work for pay outside of the household while continuing to function as a member within the household (Heilman \& Chen, 2003; Kanter, 1977; Moore, 1999; Parker, 1967), an assumption that may help explain the increasing numbers of women business owners. Researchers have found that women who choose self-employment report that family concerns are a primary motivator (Buttner \& Moore, 1997; Barbato, DeMartino \& Jacques, 2009; DeMartino \& Barbato, 2003), and the presence of children at home has been found to be predictive of self-employment among women (Caputo \& Dolinsky, 1998; Carr, 1996). In a study of female and male entrepreneurs with MBAs, DeMartino and Barbato (2003) found gender differences in reported motivation for selfemployment. Women were more likely to say that they chose self-employment because of family obligations and to gain career flexibility; men were more likely to report wealth creation as a motivator.

Surprisingly, there is limited empirical evidence supporting self-employment as an especially effective tactic for balancing work and family demands. Loscocco (1997), for example, found that among the self-employed women she interviewed, the needs of the business and the needs of children often conflicted. Neider (1987) reported that 69 percent of the women business owners in her study were divorced, and many blamed the breakup of their marriage on the emphasis they placed on their businesses. Female small business owners in Hisrich and Brush's (1984) study reported that the demands of the business impinged on their personal lives, and Stoner, Hartman, and Arora (1990) found substantial work-to-family conflict among self-employed women.

More recent research compares the experiences of the self-employed to the organizationally employed. For example, Tetrick, Slack, Da Silva, and Sinclair (2000) found that conflict between one's job and personal life did not differ among owners, managers, and employees. Parasuraman and Simmers (2001) found that the self-employed reported more general work-to-family (W $\rightarrow \mathrm{F}$ ) conflict than employees while Reynolds and Renzulli (2005) found that the self-employed had less "work interferes with life" conflict but more "life interferes with work" conflict. Prottas (2007) found that translators who worked as independent contractors reported less $\mathrm{W} \rightarrow \mathrm{F}$ conflict but more family-to-work $(\mathrm{F} \rightarrow \mathrm{W})$ than either owners or employees of translation companies. Analyzing a large $(n=3,504)$ national sample, Prottas and Thompson (2006) found that independent contractors reported less $\mathrm{W} \rightarrow \mathrm{F}$ conflict than either owners or employees but found no differences with respect to $\mathrm{F} \rightarrow \mathrm{W}$ conflict.

That self-employment appears not to be a clearly beneficial strategy for managing work and family may be due to selfemployment being more stressful with greater job pressures related to the high failure rate of small businesses, longer work hours, or lack of vacation time (Prottas \& Thompson, 2006; Thompson, Kopelman, \& Schriescheim, 1992). However, it is also possible that researchers have been focusing on 
either an incomplete array of possible outcomes or the wrong criterion. As with research on the organizationallyemployed, research on the self-employed has been rooted in scarcity theories that emphasize the conflictive nature of work and family interactions rather than possible positive spillovers between the domains (Greenhaus \& Powell, 2006; Kossek \& Ozeki, 1998). However, it may be that the benefits of self-employment are less likely to be found in the reduction of the negative or conflictive interactions between the two domains than in the enbancement of positive or facilitative interactions. An emerging stream of theory and research has examined positive outcomes of the work-family interface among employees in the forms of enrichment, positive spillover, enhancement, and facilitation (e.g., Greenhaus \& Powell, 2006). This emphasis may have particular relevance for understanding the work and family relationships of selfemployed people. This research contributes to the prior research by measuring and comparing positive spillovers as well as conflict.

There is theoretical and empirical support for the view that the interface between work and family of the selfemployed might qualitatively differ from that of employees. Building on Parker's (1967) work, Kanter (1977) argued that some occupations are highly absorptive (i.e., they demand high levels of commitment from the worker and define the context for family life), and as a result, "work and family may be so closely intertwined as to make it virtually impossible to consider one without considering the other" (p.26). Absorptive occupations may diminish or minimize boundaries between work and family, thus creating highly integrated, permeable boundaries rather than segmented domains (Ashforth, Kreiner, \& Fugate, 2000). Because of the nature of owning one's own business (e.g., the owner's financial wellbeing is often dependent on the success of the business), it seems likely that much self-employment is highly absorptive. Consequently, family and work domains may be more integrated for the self-employed than for the organizationally employed. In fact, Thompson et al. (1992) found that job and life satisfaction were more strongly related for the selfemployed than for employees, thus providing initial empirical support for Kanter's views about the absorptive nature of self-employment.

To further understand the ways in which work and family are connected for the self-employed, the work-family literature is instructive. First, research suggests that the interactions between work and family are bi-directional in nature with antecedents and consequences that differ depending on whether the influence is from work-to-family or from familyto-work. Second, both the negative and positive interactions between work and family appear to be multidimensional in nature. Conflict has been described in terms of three dimensions: time-, strain-, and behavior-based conflict (Greenhaus \&
Beutell, 1985). Positive spillover or enrichment occurs when positive experiences in one role are transferred to another role (Greenhaus \& Powell, 2006) and appears to have multiple dimensions. Hanson, Hammer, and Colton (2006) argued that positive spillover has two dimensions: an affective dimension (i.e., affect or emotion spills over from one role to another) and an instrumental dimension (i.e., skills, abilities, and values developed in one role are applied in another role). Carlson, Kacmar, Wayne and Grzywacz (2006) suggested additional dimensions (e.g., capital, which occurs when involvement in work enhances personal resources such as confidence, or self esteem). Third, conflict and positive spillover are orthogonal constructs and are not simply opposite ends of the same continuum (Frone, 2003; Greenhaus \& Powell, 2006). While there are many terms for related constructs regarding the interactions between domain roles, we use the terms conflict to refer to negative interactions and positive spillover to refer to beneficial ones, distinguish between work and family domains, and use $\mathrm{W} \rightarrow \mathrm{F}$ and $\mathrm{F} \rightarrow \mathrm{W}$ to indicate directionality.

\section{Hypotheses}

The Conservation of Resources Theory (COR; Hobfoll, 1989; 2001) is useful for making predictions about the degree to which positive spillover and work-family conflict are related to work arrangement. Hobfoll argued that people strive to obtain, build, and protect resources (e.g., objects such as their home or conditions such as financial security) and they experience stress when resources are lost or threatened with loss. He further argued that resource loss is more salient than resource gain, and that individuals with greater resources are more capable of resource gain.

In COR terms, the self-employed have a major resource advantage over the organizationally employed as they tend to have greater job autonomy (Hundley, 2001; Parasuraman \& Simmers, 2001; Prottas, 2007; Prottas \& Thompson, 2006; Tetrick et al., 2000). Although self-employment is often characterized by longer hours, greater risk, and more job pressures (Thompson et al., 1992), greater autonomy might offset those conditions. According to Karasek's (1979) demandscontrol theory, having control over one's job diminishes the impact of demands on stress and health. Research has demonstrated that individuals' perceptions of personal control (i.e., beliefs about their ability to change their environment) were associated with enhanced health and well-being (Ganster, Fox, \& Dwyer, 2001). Similarly, Grzywacz and Marks (2000) found that decision latitude, an aspect of job autonomy, was related to positive spillover between work and family, and Voydanoff (2004) found that job autonomy was positively related to work to family facilitation. Further, job autonomy has been found to be negatively related to $\mathrm{W} \rightarrow \mathrm{F}$ conflict (Parasuraman \& Simmers, 2001; Prottas, 2007; Prottas \& 
Thompson, 2006). Interestingly, Parasuraman, Purohit, Godshalk, and Beutell (1996) found that job autonomy was negatively related to $\mathrm{F} \rightarrow \mathrm{W}$ conflict but not $\mathrm{W} \rightarrow \mathrm{F}$, whereas Reynolds and Renzulli (2005) found it was negatively related to $\mathrm{W} \rightarrow \mathrm{F}$ conflict but not $\mathrm{F} \rightarrow \mathrm{W}$.

Following both COR and the demands-control theory, we expected that job autonomy would serve as an important, dominant resource for the self-employed such that they would experience higher levels of positive $\mathrm{W} \rightarrow \mathrm{F}$ spillover and lower levels of both $\mathrm{W} \rightarrow \mathrm{F}$ and $\mathrm{F} \rightarrow \mathrm{W}$ conflict. Further, we expected that after controlling for the effects of autonomy, any differences in positive spillover and conflicts would diminish.

\section{H1a. The self-employed will report less $W \rightarrow F$ and $\mathrm{F} \rightarrow \mathrm{W}$ conflict than employees.}

H1b. The differences between the self-employed and employees with respect to $W \rightarrow F$ and $F \rightarrow W$ conflict will be attenuated after controlling for job autonomy. H2a. The self-employed will report more positive $W \rightarrow F$ spillover than employees.

H2b. The differences between the self-employed and employees with respect to positive $W \rightarrow F$ spillover will be attenuated after controlling for job autonomy.

\section{Gender and Self-employment}

Self-employed women and men appear to have varying motivations for seeking self-employment. As discussed earlier, women's decisions to seek self-employment are more likely to be affected by family structure, including factors such as marital status, spousal income, and presence of children (Carr, 1996; DeMartino \& Barbato, 2003). Women, regardless of employment status, continue to spend more time on child and general homecare responsibilities than men, and are more likely to work part time and at home (Bond et al., 2003; Parasuraman \& Simmers, 2001; Reynolds \& Renzulli, 2005). Gender role theory suggests that normative, gender-based expectations influence women's and men's decisions about how much time to allocate to parenting and home roles, with women often taking on the primary responsibility for the family/home sphere (Gutek, Searle, \& Klepa, 1991; Parasuraman \& Simmers, 2001; Reynolds \& Renzulli, 2005). However, while working women may in general have different role demands than working men in general, there is no clear theoretical reason to believe that self-employment will represent a more or less effective method of managing work and family roles for women than it is for men. We will compare the levels of conflict and positive spillover by subsamples of men and women on a post hoc basis.

\section{Method}

\section{Sample}

Data were collected from 280 Certified Public Accountants
(CPAs) working in Mid-Atlantic states. The sample frame consisted of CPAs whose names, business addresses, and email addresses were available from publicly accessible directories of state professional associations. The initial sampling frame was assembled to produce a final sample that was over-represented by self-employed. Email pre-advices were sent, followed by a mailing of surveys with stamped self-addressed return envelopes. Three to four weeks after the mailings, email follow-ups were sent (which included a link where they could download an electronic version of the survey). The response rate was 31 percent of delivered mailings.

Demographic variables assessed included gender, age, individual income, and marital status (married or living with a partner).

Work Arrangement was determined by asking participants to classify themselves in terms of the following seven categories: sole practitioner (with no full-time employees other than yourself); sole practitioner (with one or more nonCPA employees); partner (with at least one-third partnership interest) in a public accountancy firm; partner (with less than one-third partnership interest) in a public accountancy firm; employee of a public accountancy firm (nonpartner); employee of other than a public accountancy firm; other. Those who chose "other" provided sufficient information to be classified as owners of firms. As some large public accountancy firms have thousands of "partners," for purposes of this study we felt it necessary to distinguish between partners whose ownership interests were sufficiently large to provide them with rights and responsibilities that are more generally associated with ownership. Partners with less than one-third partnership interests and employees of public accountancy and other organizations were classified as employees while partners with at least one-third partnership interest and sole practitioners were classified as selfemployed.

Job Autonomy was assessed by four items from Beehr (1976) (e.g., "I have enough freedom as to how I do my work"). Participants were asked to indicate whether they agreed that each statement described their job with a 7-point Likert scale (e.g., strongly disagree, neither disagree/agree, strongly agree). Items were scored so that higher values indicated greater autonomy and averaged. The Cronbach alpha coefficient of internal reliability was .94 .

Work Flexibility was assessed by four items from Clark (2002) (e.g., "I could easily take a day off from work, if I wanted to"). One item, "I can carry out non-work projects during spare time at work," was changed slightly to omit the reference to an employer to make it appropriate for selfemployed. The same response options were provided. The alpha was .85. As the autonomy and flexibility items were associated with constructs that seemed conceptually related, we conducted an exploratory factor analysis (principle com- 
ponent with Varimax rotation) on the eight items. The result was a single factor solution (Eigenvalue of 5.4, accounting for $67.9 \%$ of variance). For this study we used an eight-item scale of autonomy/flexibility with an alpha of .92 .

Conflict and Positive Spillovers were assessed by 16 items. $\mathrm{F} \rightarrow \mathrm{W}$ conflict was assessed by four items from Gutek et al., (1991) (e.g.," I'm often too tired at work because of the things I have to do at home" and "People that I work with dislike how often I am preoccupied with my personal life"). $\mathrm{W} \rightarrow \mathrm{F}$ conflict was assessed by four items adapted from Kopelman, Greenhaus, and Connolly (1983) (e.g., "My work takes up time I would rather spend with my family"). In one item, "supervisors and peers" was changed to "people that I work with" to better suit self-employed participants. Positive $\mathrm{F} \rightarrow \mathrm{W}$ spillover was assessed by four items. Two were from the 2002 National Study of the Changing Workforce (Bond et al., 2003) ("I am often in a better mood at my job because of my family or personal life" and "I often have more energy to do my job because of my family or personal life") and two were developed for this study ("Talking with my friends or family often helps me deal with problems at work" and" My friends or family often do things that help me get my work done or do my job better"). Positive $\mathrm{W} \rightarrow \mathrm{F}$ spillover was assessed by four parallel items. All items had 7-point Likerttype scales as above.

The internal reliabilities were adequate for three out of the four scales: $\mathrm{F} \rightarrow \mathrm{W}$ conflict, .69; $\mathrm{W} \rightarrow \mathrm{F}$ conflict, .79; and positive $\mathrm{F} \rightarrow \mathrm{W}, .69$. However, the internal reliability of positive $\mathrm{W} \rightarrow \mathrm{F}^{\prime}$ was only .50. We performed exploratory factor analysis on all 16 items using Varimax rotation. Five factors with eigenvalues over 1 emerged. The four $\mathrm{W} \rightarrow \mathrm{F}$ conflict items loaded on the first (accounting for $21.9 \%$ of variance), the four positive $\mathrm{F} \rightarrow \mathrm{W}$ items loaded on the second (accounting for $16.2 \%$ of variance) and the four $\mathrm{F} \rightarrow \mathrm{W}$ conflict items loaded on the third (11.3\% of variance). However, the two positive $\mathrm{W} \rightarrow \mathrm{F}$ items relating to obtaining instrumental help loaded on the fourth (7.7) and the two positive $\mathrm{W} \rightarrow \mathrm{F}$ items relating to mood and energy loaded on the fifth (6.4\%). The alpha of the two instrumental items was .74 and the alpha of the two mood/energy items was .56. Rather than using a fouritem multidimensional measure with a low reliability to assess positive $\mathrm{W} \rightarrow \mathrm{F}$ spillover, we used in this analysis a measure consisting of the two instrumental help items only.

\section{Results}

The basic statistics and intercorrelations appear in Table 1.As conflict and positive spillovers are conceptually associated and likely to be correlated, we first tested our hypotheses about the differences between the self-employees through multivariate analysis of variance with work arrangement as the fixed factor $(1=$ self-employed; $0=$ employee $)$ and $\mathrm{F} \rightarrow \mathrm{W}$ and $\mathrm{W} \rightarrow \mathrm{F}$ conflict and positive $\mathrm{F} \rightarrow \mathrm{W}$ and $\mathrm{W} \rightarrow \mathrm{F}$ spillovers as the dependent variables. We conducted four hierarchical regressions (with individual demographics as the first step,

\begin{tabular}{|c|c|c|c|c|c|c|c|c|c|c|c|c|c|c|}
\hline & Variables & M & SD & $\mathrm{N}$ & 1 & 2 & 3 & 4 & 5 & 6 & 7 & 8 & 9 & 10 \\
\hline 1. & Work arrangement & .60 & .49 & 280 & - & & & & & & & & & \\
\hline 2. & Age & 49.78 & 10.15 & 277 & $.27^{* * * *}$ & - & & & & & & & & \\
\hline 3. & Sex & .35 & .48 & 279 & .05 & $-.28^{* * * *}$ & - & & & & & & & \\
\hline 4. & Marital Status & .88 & .33 & 277 & -.00 & .06 & $-.22^{* * * *}$ & - & & & & & & \\
\hline 5. & $\begin{array}{l}\text { Individual Income } \\
(\$ 000 \text { 's })\end{array}$ & 144.7 & 130.0 & 244 & $-.32^{* * *}$ & .10 & $-.27^{* * * *}$ & .05 & - & & & & & \\
\hline 6. & $\begin{array}{l}\text { Autonomy \& } \\
\text { flexibility }\end{array}$ & 6.15 & 1.09 & 280 & $.42^{* * *}$ & $.35^{* * * * *}$ & -.03 & $.13^{*}$ & .06 & $(.92)$ & & & & \\
\hline 7. & $\mathrm{~W} \rightarrow \mathrm{F}$ conflict & 4.27 & 1.41 & 279 & $-.20^{* * *}$ & $-.35^{\text {***** }}$ & .08 & -.01 & .10 & $-.34^{* * * *}$ & $(.79)$. & & & \\
\hline 8. & $\mathrm{~F} \rightarrow \mathrm{W}$ conflict & 3.11 & 1.03 & 279 & -.04 & $-.30^{* * * *}$ & $.18^{* *}$ & -.06 & $-.13^{*}$ & $-.30^{* * * *}$ & $.65^{* * * *}$ & $(.60)$. & & \\
\hline 9. & $\begin{array}{l}\text { Positive } \mathrm{F} \rightarrow \mathrm{W} \\
\text { spillover }\end{array}$ & 4.21 & 1.23 & 274 & .07 & - -08 & $.17^{* *}$ & .08 & -.08 & .05 & $.12^{*}$ & .11 & (.69.) & \\
\hline 10. & $\begin{array}{l}\text { Positive } \mathrm{W} \rightarrow \mathrm{F} \\
\text { spillover }\end{array}$ & 3.36 & 1.52 & 273 & .04 & $-.13^{*}$ & $.19^{* *}$ & .04 & -.08 & .08 & $.17^{* * *}$ & $.26^{* * * *}$ & $.28^{* *}$ & $(.74)$. \\
\hline
\end{tabular}

Basic Statistics and Correlations

Note. Categorical variables: Work Arrangement: $1=$ self-employed, $0=$ employee; Sex: $1=$ Female, $0=$ Male;

Marital: $1=$ married, $0=$ Single. $\mathrm{W} \rightarrow \mathrm{F}=$ Work-to-Family. $\mathrm{F} \rightarrow \mathrm{W}=$ Family-to-Work.

${ }^{*} p<.05$, two-tailed; ${ }^{* *} p<.01$, two-tailed; $* * * p<.001$, two-tailed. 
work arrangement as the second, and autonomy/flexibility as the third). For our post hoc analysis of gender effects, we split the participants into two subsamples of men and women and repeated the multivariate analysis. Our discussion addresses effect sizes as well as statistical significance. For correlations, we use Cohen's (1992) thresholds for $r$ as small, 10; medium, 30 ; large, .50 . We calculated the partial eta-square $\left(\eta_{\rho}{ }^{2}\right)$ as the effect size for the multivariate and univariate relationships with .01 for a small effect size, .06 for medium, and .14 for large (Stevens, 2002).

The majority of the 280 participants were self-employed $(60 \%)$, male $(65 \%)$ and married or living in a similar relationship (88\%). Mean age was 49.8 years $(\mathrm{sd}=10.15)$ and median income was $\$ 100,000$. As shown in Table 1 , consistent with prior findings, the self-employed were older $(r=.27, p<.001)$ and reported higher levels of job autonomy/flexibility $(r=.42$, $p<.001)$. However, this sample differed from other studies in that being self-employed was negatively related to income $(r=-.32, p<.001)$. This unusual finding is likely attributable to the number of employees with the CPA credential who had become partners in the very large public accountancy firms or senior treasury or finance officers in large corpora- tions. Many of the self-employed, in contrast, were owners in relatively small public accountancy firms.

We found very limited support for hypothesis 1a, which predicted that the self-employed would have less $\mathrm{W} \rightarrow \mathrm{F}$ and $\mathrm{F} \rightarrow \mathrm{W}$ conflict. The zero-order correlation with work arrangement was $-.20, p<.05$ for $\mathrm{W} \rightarrow \mathrm{F}$ but insignificant for $\mathrm{F} \rightarrow \mathrm{W}$ (Table 1). The multivariate univariate $F$ statistic based on the Wilks lambda for work arrangement was $F(4,268)=4.47, p<$ $.01, \eta_{\rho}^{2}=.06$. However, only the univariate relationship between work arrangement and negative $\mathrm{W} \rightarrow \mathrm{F}$ spillover was statistically significant $\left(\mathrm{p}<.01, \eta_{\rho}^{2}=.04\right)$ and work arrangement when entered in the second step of the hierarchical regression was not significant (Table 2a).

Our hypothesis $1 \mathrm{~b}$ that autonomy/flexibility would attenuate the relationship between self-employment and lower $\mathrm{W} \rightarrow \mathrm{F}$ conflict was supported. As shown in Table 1, autonomy/flexibility was related as expected to both $\mathrm{W} \rightarrow \mathrm{F}$ $(r=-.34, p<.001)$ and $\mathrm{F} \rightarrow \mathrm{W}(r=-.30, p<.001)$. When added as the third step in the hierarchical regression on $\mathrm{W} \rightarrow \mathrm{F}$ conflict, autonomy/flexibility was significant $(B=$ $.27, p<.001)$ and accounted for an additional 6 percent of variance and the $B$ coefficient for work arrangement was

\begin{tabular}{|c|c|c|c|c|c|c|}
\hline \multirow[b]{3}{*}{ Independent Variables } & \multicolumn{6}{|c|}{ Dependent Variables } \\
\hline & \multicolumn{3}{|c|}{ Work-to-Family Conflict } & \multicolumn{3}{|c|}{ Family-to-Work Conflict } \\
\hline & Step 1 & Step 2 & Step 3 & Step 1 & Step 2 & Step 3 \\
\hline Age & $-.39^{* * * *}$ & $-.38^{* * * * *}$ & $-.32^{* * * *}$ & $-.32^{* * * *}$ & $-.33^{* * * *}$ & $-.27^{* * * *}$ \\
\hline Sex & -.00 & -.00 & -.02 & .03 & .03 & .05 \\
\hline Individual Income & $.14^{*}$ & .13 & .00 & -.08 & -.07 & -.02 \\
\hline Work Arrangement & & -.04 & .07 & & .02 & $.14 \dagger$ \\
\hline Autonomy/Flexibility & & & $-.27^{* * * *}$ & & & $-.28^{* * * *}+y-1$ \\
\hline$R^{2}$ & .16 & .16 & .22 & .12 & .12 & .18 \\
\hline Total $F$ & $15.36^{\text {**** }}$ & $11.60^{* * * *}$ & $13.23^{* * * *}$ & $11.15^{\text {***** }}$ & $8.36^{* * * *}$ & $10.72^{* * * *}$ \\
\hline$\Delta R^{2}$ & - & .00 & .06 & - & .00 & .06 \\
\hline$\Delta F$ & - & .40 & $16.72^{* * * *}$ & - & .11 & $17.80^{* * * *}$ \\
\hline $\mathrm{df}$ & 3,239 & 4,238 & 5,237 & 3,239 & 4,238 & 5,237 \\
\hline
\end{tabular}

Note. Categorical variables: $\operatorname{sex}(1=$ female, $0=$ male $)$; work arrangement $(1=$ self-employed, $0=$ employee.

In each hierarchical regression, blocks of variables were entered in successive order:

Step 1, demographic variables; step 2, work arrangement; step 3, autonomy/flexibility.

$\dagger p=.06$.two-tailed; ${ }^{*} p<.05$, two-tailed; ${ }^{* * * *} p<.001$, two-tailed. 
not significant $(p=.35)$. Similarly, when autonomy/flexibility was entered as the third step in the hierarchical regression on $\mathrm{F} \rightarrow \mathrm{W}$ conflict, it was significant $(B=-.28, p<.001)$ and accounted for an additional 6 percent of variance.

We found no support for our hypothesis $2 \mathrm{a}$, which predicted that both positive $\mathrm{W} \rightarrow \mathrm{F}$ and $\mathrm{F} \rightarrow \mathrm{W}$ spillovers would be greater for the self-employed. As shown in Table 1, the correlations were not statistically significant and did not reach the threshold for a small effect size. Similarly, univariate relationships between work arrangement and either direction of positive spillover were not statistically.

Contrary to our expectations, there were no relationships between autonomy/flexibility and either form of positive spillover. As shown in Table 1, the correlations were .08 for positive $\mathrm{F} \rightarrow \mathrm{W}$ and .04 for $\mathrm{W} \rightarrow \mathrm{F}$.Additionally, as shown in Table $2 \mathrm{~b}$, when autonomy/flexibility was entered as the third step in the hierarchical regressions (after the demographics and work arrangement) it was not significant for positive $\mathrm{F} \rightarrow \mathrm{W}$ $(p=.35)$ although it was for $\mathrm{W} \rightarrow \mathrm{F}(B=.16, p<.05)$ but only accounted for 2 percent of additional variance.

However, the results of our multivariate analysis of subsamples of $\mathbf{1 7 6}$ men and 97 women with work arrangement as the fixed factor revealed interesting differences. In each subsample, the multivariate F statistics were significant $(p<$ .01) and the effect sizes exceeded the threshold for medium: men, $\eta_{\rho}^{2}=.09$, women, $\eta_{\rho}^{2}=.13$. The smaller female subsample size provided less statistical power than did the male subsample; we will discuss all univariate relationships with effect sizes that reached the threshold for small regardless of their levels of statistical significance. Among males, the selfemployed had superior outcomes: less $\mathrm{F} \rightarrow \mathrm{W}\left(p<.05, \eta_{\rho}^{2}=\right.$ $.02)$ and $\mathrm{W} \rightarrow \mathrm{F}$ conflict $\left(\phi<.01, \eta_{\rho}^{2}=.06\right)$, and more positive $\mathrm{F} \rightarrow \mathrm{W}\left(\phi=.12, \eta_{\rho}^{2}=.01\right)$ spillover (with no difference with respect to positive $\mathrm{W} \rightarrow \mathrm{F}$ spillover). In contrast, female selfemployed had inferior outcomes with more negative $\mathrm{F} \rightarrow \mathrm{W}$ conflict $\left(p=.13, \eta_{\rho}^{2}=.02\right)$ and less $\mathrm{W} \rightarrow \mathrm{F}\left(p=.16, \eta_{\rho}^{2}=.02\right)$ spillovers (with no differences with respect to either positive $\mathrm{F} \rightarrow \mathrm{W}$ or $\mathrm{W} \rightarrow \mathrm{F}$ spillovers). In short, the results for men were similar to those we had originally hypothesized while those for women were quite different.

\section{Discussion}

We found limited support for the view that self-employment enables people to improve the quality of the interface

\begin{tabular}{|c|c|c|c|c|c|c|}
\hline \multirow[b]{3}{*}{ Independent Variables } & \multicolumn{6}{|c|}{ Dependent Variables } \\
\hline & \multicolumn{3}{|c|}{ Positive Work-to-Family Spillover } & \multicolumn{3}{|c|}{ Positive Family-to-Work Spillover } \\
\hline & Step 1 & Step 2 & Step 3 & Step 1 & Step 2 & Step 3 \\
\hline Age & -.05 & -.08 & -.12 & -.00 & -.02 & -.04 \\
\hline Sex & $.15^{*}$ & $.14^{*}$ & $.13 \dagger$ & $.15^{*}$ & $.15^{*}$ & $.15^{*}$ \\
\hline Individual Income & -.04 & -.01 & -.04 & -.03 & -.01 & -.02 \\
\hline Work Arrangement & & .09 & .03 & & .07 & .04 \\
\hline Autonomy/Flexibility & & & $.16^{*}$ & & & .07 \\
\hline$R^{2}$ & .03 & .04 & .06 & .03 & .03 & .04 \\
\hline Total $F$ & $2.75^{*}$ & $2.44^{*}$ & $2.93^{*}$ & 2.20 & 1.88 & 1.68 \\
\hline$\Delta R^{2}$ & - & .01 & .02 & - & .00 & .00 \\
\hline$\Delta F$ & - & 1.50 & $4.74^{*}$ & - & .92 & .89 \\
\hline $\mathrm{df}$ & 3,235 & 4,234 & 5,233 & 3,234 & 4,235 & 5,234 \\
\hline
\end{tabular}

Note. Categorical variables: $\operatorname{sex}(1=$ female, $0=$ male);

work arrangement $(1=$ self-employed, $0=$ employee.

In each hierarchical regression, blocks of variables were entered in successive order:

Step 1, demographic variables; step 2, work arrangement; step 3, autonomy/flexibility.

$\dagger p=.06$.two-tailed; $* p<.05$, two-tailed; ${ }^{* * * *} p<.001$, two-tailed. 
between their work and family roles. The self-employed reported substantially greater job autonomy/flexibility than employees (with an effect size that approached the threshold for large). Job autonomy and flexibility appears to have allowed them to have taken actions or experienced a sense of control such that they reported less conflict from the work to family domains (with an effect size that approached the threshold for medium). However, once job autonomy and flexibility were controlled for, there was no benefit associated with self-employed left to be explained by other characteristics.

There seemed to be important differences between men and women. With respect to $\mathrm{W} \rightarrow \mathrm{F}$ conflict both selfemployed men and women reported lower levels than their employee counterparts. However, the effect sizes of the differences for men were larger than that for women $\left(\eta_{\rho}^{2}=.06\right.$ vs. $\left.\eta_{\rho}^{2}=.02\right)$. With respect to $\mathrm{F} \rightarrow \mathrm{W}$ conflict, we found no relationships with self-employment in the full sample but we did when we divided the sample into men and women. Among men, the self-employed report lower levels of conflict relative to male employees with an effect size that approached the threshold for medium $\left(\eta_{\rho}^{2}=.05\right)$. In contrast, women report higher levels with an effect size that barely exceeded the threshold for small $\left(\eta_{\rho}^{2}=.02\right)$. Similarly, with respect to positive $\mathrm{F} \rightarrow \mathrm{W}$ spillover there was an indication that self-employed men were benefited (albeit weak as $p$ only reached .12 although the effect size of the difference reached the threshold of .01 for small).

Further research is required to explore the reasons for these differences. As shown in Table 1, there was no difference between men and women with respect to the amount of autonomy and flexibility they had and there were no differences between the subsamples of female self-employed and their counterparts. Other aspects of the interface between the male and female self-employed might differ. It is possible that the family members of a self-employed male more readily recognize and respect him in his role as "worker" and reduce their demands while the family members of women might not differentiate the roles and make the same level of demands as they would if she were not working.

This study produced two results that may be of interest to work-family scholars. First, the finding that responses to job autonomy and flexibility items loaded on the same factor should lead researchers to consider whether they are indeed two separate constructs or whether it is worth asking participants to distinguish between facets of autonomy (such as with respect to when and how work is done as opposed to how it is done). Second, the lack of relationships between autonomy/flexibility and positive spillovers is surprising as autonomy seems to have very strong, negative relationships with conflict and would be expected to be a crucial resource or ability with respect to gathering and applying the resources that could lead to enhancement or enrichment between roles.

Before discussing recommendations for future research, several limitations to this study should be mentioned. First, the internal reliabilities of our measures of conflict and positive spillover were on the lower end of adequacy and they did not assess underlying dimensions. Second, our data collection technique of self-report surveys left us with its inherent weaknesses (i.e., common source and method bias). Third, our sample was composed of CPAs who have a high level of education and satisfied demanding professional standards. This might have attenuated some of our findings through range restriction, and of course, raises questions about the generalizability of our findings to other groups and the broader population.

Future research should use newly developed and validated scales of positive spillover, such as those of Carlson et al. (2006) or Hanson et al. (2006) to examine multiple dimensions and directionality of positive spillover. With more reliable and multidimensional measures, differences might be found and factors other than autonomy might account for them.

However, as the measures of positive spillover (or enhancement or enrichment) were developed primarily within the context of organizational employment, researchers should consider adding items that would address forms of positive spillover that might not be relevant to employees (e.g., instrumental positive spillover in the form of paid or unpaid labor or the provision of financial capital from relatives). Additional items should tap forms of positive spillover that might be relevant for some employees but may be more likely for the self-employed (e.g., increased social capital from expanded social networks).

This research illustrates the imperative to conduct research on work and family in different settings and with different populations (Casper, Eby, Bordeaux, \& Lockwood, 2007: Kossek \& Ozeki, 1998). It appears evident that a fuller understanding of work and family interactions needs to take place while simultaneously examining situational factors such as work arrangement and factors such as gender. This has implications with respect to the need to collect data with a sufficient number of participants to provide statistical power for between group and subsamples analyses.

In conclusion, our analysis of the two samples provides evidence that self-employment may be a useful way to manage work and family. Relative to the organizationally employed, the self-employed men and women experience lower levels of work-to-family conflict and men experienced lower less family-to-work conflict (but women more). However, it appears that self-employment might merely have instrumental value in that it enables people to gain more control over their jobs than they could attain by working for oth- 
ers. Further research is needed to determine whether there may be additional benefits with respect to other dimensions of the work-family interface and whether the integrated nature of the lives of the self-employed-rather than a situational characteristic such as job autonomy-might account for some of the differences.

\section{Acknowledgment}

The author expresses his appreciation to Dr. Cynthia A.Thompson for her invaluable advice and guidance.

\section{References}

Ashforth, B. E., Kreiner, G. E., \& Fugate, M. (2000). All in a day's work: Boundaries and micro role transitions. Academy of Management Review, 25, 472-491.

Barbato, R., DeMartino, R., \& Jacques, P. H. (2009). The entrepreneurial motivations of nonemployer entrepreneurs. New England Journal of Entrepreneurship, 12,33-42.

Beehr,T.A. (1976). Perceived situational moderators of the relationship between subjective role ambiguity and role strain. Journal of Applied Psychology, 61, 35-40.

Bond, J.T., Thompson, C., Galinsky, E., \& Prottas, D. (2003). Highlights of the National Study of the Changing Workforce, No. 3, 2002. New York: Families and Work Institute.

Buttner, E. H., \& Moore, D. P. (1997). Women's organizational exodus to entrepreneurship: Self-reported motivations and correlates with success. Journal of Small Business Management, 35, 34-46.

Caputo, R. K., \& Dolinsky,A. (1998). Women's choice to pursue self-employment: the role of financial and human capital of household members. Journal of Small Business Management, 36, 8-17.

Carlson, D. S., Kacmar, K. M., Wayne, J. H., \& Grzywacz, J. G. (2006). Measuring the positive side of the work-family interface: Development and validation of a work-family enrichment scale. Journal of Vocational Behavior, 68, 131-164.

Carr, D. (1996). Two paths to self-employment? Women's and men's self-employment in the United States, 1980. Work \& Occupations, 23, 26-53.

Casper,W. J., Eby, L. T., Bordeaux, C., \& Lockwood,A. (2007). A review of research methods in IO/OB work-family research. Journal of Applied Psychology, 92, 28-43.

Clark, S. C. (2002). Communicating across the work/home border. Community, Work, \& Family, 5, 23-48.

Cohen, J. 1992. A power primer. Psychological Bulletin, 112, 155-159.

DeMartino, R., \& Barbato, R. (2003). Differences between women and men MBA entrepreneurs: exploring family flexibility and wealth creation as career motivators. Journal of Business Venturing, 18, 815-832.

Frone, M. R. (2003). Work-family balance. In J. C. Quick \& L. E. Tetrick (Eds.), Handbook of Occupational Health Psychology: 143-162. Washington, D.C.:American Psychological Association.

Ganster, D. C., Fox, M. L., \& Dwyer, D. J. (2001). Explaining employees' health care costs:A prospective examination of stressful job demands, personal control, and physiological reactivity. Journal of Applied Psychology, 86, 954-964.

Greenhaus, J. H., \& Beutell, N. J. (1985). Sources of conflict between work and family roles. Academy of Management Review, $10,76-88$.

Greenhaus, J. H., \& Powell, G. N. 2006. When work and family are allies:A theory of work-family enrichment. Academy of Management Review, 31:72-92.

Grzywacz, J. G., \& Marks, N. F. (2000). Reconceptualizing the work-family interface:An ecological perspective on the correlates of positive and negative spillover between work and family. Journal of Occupational Health Psychology, 5 , 111-126.

Gutek, B. W., Searle, S., \& Klepa, L. 1991. Rational versus gender role explanations for work-family conflict.Journal of Applied Psychology, 76: 560-568.

Hanson, G. C., Hammer, L. B., \& Colton, C. L. (2006). Development and validation of a multidimensional scale of perceived work-family positive spillover.Journal of Occupational Health Psychology, 11, 249-265.

Heilman, M. E., \& Chen, J. K. (2003). Entrepreneurship as a solution:The allure of self-employment for women and minorities. Human Resource Management Review, 13,347-364. 
Hisrich, R.D., \& Brush, C. (1984).The women entrepreneur: Management skills and business problems. Journal of Small Business Management, 22, 30-37.

Hobfoll, S. E. (1989). Conservation of resources: A new attempt at conceptualizing stress. American Psychologist, 44, 513-524.

Hughes, K. D. (2003). Pushed or pulled? Women's entry into self-employment and small business ownership. Gender, Work and Organization, 10, 443-454.

Hundley, G. (2001). What and when are the self-employed more satisfied with their work? Industrial Relations, 40, 293-316.

Kanter, R. M. (1977). Work and family in the United States: A critical review and agenda for research and policy. New York: Russell Sage Foundation.

Karasek, R. (1979). Job demands, job decision latitude and mental strain: Implications for job redesign. Administrative Science Quarterly, 24, 285-306.

Kopelman, R. E., Greenhaus, J. H., \& Connolly,T. F. (1983). A model of work, family and interrole conflict:A construct validation study. Organizational Behavior and Human Performance, 32, 198-215.

Kossek, E. E., \& Ozeki, C. (1998). Work-family conflict, policies, and the job-life satisfaction relationship: A review and directions for organizational behavior-human resources research. Journal of Applied Psychology, 83, 139-149.

Loscocco, K.A. (1997). Work-family linkages among self-employed women and men. Journal of Vocational Behavior, 50, 204-226.

Moore, D. P. (1999). Women entrepreneurs: Approaching a new millennium. In G. N. Powell (ed.), Handbook of Gender and Work (pp. 371-389). Sage Publishers:Thousand Oaks, CA.

Neider, L. (1987). A preliminary investigation of female entrepreneurs in Florida.Journal of Small Business Management, 25 , 22-29.

Parasuraman, S., \& Simmers, C.A. (2001). Type of employment, work-family conflict and well-being:A comparative study. Journal of Organizational Behavior, 22, 551-568.

Parasuraman, S., Purohit, Y. S., Godshalk, V. M., \& Beutell, N. J. (1996). Work and family variables, entrepreneurial career success and psychological well-being. Journal of Vocational Behavior, 48, 275-300.

Parker S. R. (1967). Industry and the family. In S. R. Parker, R. K. Brown, J. Child, \& M. A. Smith. (Eds.), Sociology of Industry, 45-55. New York: Frederick A. Praeger.

Prottas, D. J. (2007). Attitudes toward occupation, job life, and family:Translators as independent contractors, owners, and employees. Journal of Business and Entrepreneurship, 19, 16-30.

Prottas, D. J., \& Thompson, C.A. (2006). Stress, satisfaction, and the work-family interface:A comparison of self-employed business owners, independents, and organizational employees. Journal of Occupational Health Psychology, 11, 366-378.

Quinn, R.P., \& Staines, G.L. (1979). The 1977 quality of employment survey. Survey Research Center. Ann Arbor, MI: Survey Research Center.

Reynolds, J., \& Renzulli, L.A. (2005). Economic freedom or self-imposed strife:Work-life conflict, gender, and self-employment. Entrepreneurship Research in the Sociology of Work, 15, 33-60.

Stevens, J. P. (2002). Applied multivariate statistics for the social sciences. Mahwah, NJ: Lawrence Erlbaum.

Stoner, C. R., Hartman, R. I., \& Arora, R. (1990). Work-home conflict in female owners of small businesses: An exploratory study. Journal of Small Business Management, 28, 30-38.

Tetrick, L. E., Slack, K. J., Da Silva, \& Sinclair, R. R. (2000). A comparison of stress-strain process for business owners and nonowners: Differences in job demands, emotional exhaustion, satisfaction, and social support.Journal of Occupational Health Psychology, 5, 464-476.

Thompson, C.A., Kopelman, R.E., \& Schriesheim, C.A. (1992). Putting all one's eggs in the same basket:A comparison of commitment and satisfaction among self- and organizationally employed men.Journal of Applied Psychology, 77, 738-743.

Voydanoff, P. (2004). The effects of work demands and resources on work-to-family conflict and facilitation. Journal of Marriage and Family, 66, 398-412. 


\section{About the Author}

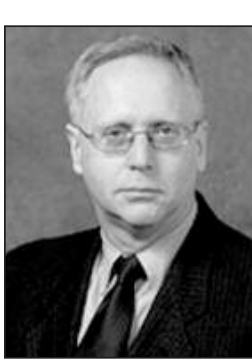

David Protas (prottas@adelphi.edu) is an Associate Professor at the Robert W.Willumstad School of Business at Adelphi University. He teaches undergraduate and graduate classes in human resource management and negotiation. He has published empirical and theoretical articles in the work/family area. His other areas of research interest include psychological characteristics of the self-employed and outcomes related to selfemployment, perceived behavioral integrity, and leadership and management practices. He received his PhD in Organizational Behavior and Human Resource Management from the CUNY Graduate Center (Baruch College) after spending more than two decades as a corporate and investment banker in New York, London, Miami, and Buenos Aires. He previously earned his MBA from the University of Chicago and his BA from Vassar College. 